\title{
Mutations in shaking-B Prevent Electrical Synapse Formation in the Drosophila Giant Fiber System
}

\author{
Pauline Phelan, ${ }^{1}$ Madoka Nakagawa, ${ }^{1}$ Marian B. Wilkin, ${ }^{1}$ Kevin G. Moffat, ${ }^{2}$ Cahir J. O'Kane, ${ }^{3}$ Jane A. Davies, ${ }^{1}$ \\ and Jonathan P. Bacon'1 \\ 1Sussex Centre for Neuroscience, School of Biological Sciences, University of Sussex, Brighton BN1 9QG, '2Department \\ of Biology, University of Wanwick, Coventry CV4 7AL, and ${ }^{3}$ Department of Genetics, University of Cambridge, \\ Cambridge CB2 3EH, United Kingdom
}

The giant fiber system (GFS) is a simple network of neurons that mediates visually elicited escape behavior in Drosophila. The giant fiber (GF), the major component of the system, is a large, descending interneuron that relays visual stimuli to the motoneurons that innervate the tergotrochanteral jump muscle (TTM) and dorsal longitudinal flight muscles (DLMs). Mutations in the neural transcript from the shaking- $B$ locus abolish the behavioral response by disrupting transmission at some electrical synapses in the GFS.

This study focuses on the role of the gene in the development of the synaptic connections. Using an enhancer-trap line that expresses lac $Z$ in the GFs, we show that the neurons develop during the first $30 \mathrm{hr}$ of metamorphosis. Within the next $15 \mathrm{hr}$, they begin to form electrical synapses, as indicated by the transfer of intracellularly injected Lucifer yellow. The GFs dye- couple to the TTM motoneuron between 30 and $45 \mathrm{hr}$ of metamorphosis, to the peripherally synapsing interneuron that drives the DLM motoneurons at $-48 \mathrm{hr}$, and to giant commissural interneurons in the brain at $\sim 55 \mathrm{hr}$. Immunocytochemistry with shaking-B peptide antisera demonstrates that the expression of shaking-B protein in the region of GFS synapses coincides temporally with the onset of synaptogenesis; expression persists thereafter. The mutation shak $-B^{2}$, which eliminates protein expression, prevents the establishment of dye coupling. shaking- $B$, therefore, is essential for the assembly and/or maintenance of functional gap junctions at electrical synapses in the GFS.

Key words: electrical synapse; Drosophila; enhancer-trap; escape response; gap junction; giant fiber system; neuronal development; shaking-B gene; synaptogenesis
The functioning of neural networks relies on precise, directional communication between specific pairs of neurons. This dictates that developing neurons must form and maintain highly specific synaptic connections. Studies on selccted pathways in a variety of species, from insects to mammals, demonstrate the remarkable fidelity with which growth cones of developing neurons project to and recognize their synaptic targets (for review, see Goodman and Shatz, 1993). In Drosophila, screening for those mutants in which identified neurons fail to make the right connections has resulted in the isolation of unique sets of genes that are required for pathfinding and target recognition (Van Vactor et al., 1993; Martin et al., 1995). Less is known about the molecules that are required to regulate the assembly of functional synapses. The role of agrin in the organization of the developing vertebrate neuromuscular junction is a notable exception (Nastuk and Fallon, 1993). In Drosophila, a candidate for an analogous function at some central synapses is the shaking- $B$ gene.

shaking- $B$ (previously called Passover) was discovered by isolating mutants that fail to show a characteristic escape jump to a visual stimulus (Thomas and Wyman, 1984). This behavior is mediated by a network of well defined and accessible neurons

Received Aug. 9, 1995; revised Oct. 10, 1995; accepted Oct. 25, 1995.

This work was funded by the BBSRC, UK. The generation of line A307 was supported by Wellcome Trust Grant 034320 Z $91 / Z$ to C.J.O. We thank Richard Baines and Kevin Thompson for help with intracellular injection, Neil Bone for tutorials on the confocal microscope, and Colin Atherton and Julian Thorpe for photographic assistance.

Correspondence should be addressed to Dr. Pauline Phelan at the above address. Copyright $C 1996$ Society for Neuroscience $0270-6474 / 96 / 161101-13 \$ 05.00 / 0$ known as the giant fiber system (GFS). Visual input activates the giant fibers (GFs). T'his pair of large, descending interneurons relays the visual information to motoneurons in the mesothoracic neuromere (T2). The GFs synapse directly with the tergotrochanteral (jump) muscle motoneurons (TTMns) and indirectly, via the peripherally synapsing interncurons (PSIs), with the motoneurons of the dorsal longitudinal flight muscles (DLMs) (King and Wyman, 1980; Koto et al., 1981; Bacon and Strausfeld, 1986). Thomas and Wyman (1984) found that some mutations in shaking-B disrupt transmission at the GF-TTMn synapse and at one or both of the GF-PSI and PSI-DLMn synapses. Two of these synapses, the GF-TTMn and GF-PSI, are electrical (Tanouye and Wyman, 1980; Strausfeld and Bassemir, 1983; Bacon and Strausfeld, 1986).

Several transcripts from the shaking- $B$ locus are produced by differential splicing and alternative promoter usage and subserve different functions of the gene (Crompton et al., 1992, 1995; Krishnan et al., 1993, 1995). shaking-B(lethal) is essential for viability; loss of function mutants do not survive past the first larval instar (Baird et al., 1990; Crompton et al., 1995). In contrast, mutations in shaking-B(neural) are viable; they arc responsible for the synaptic disruption in the GFS (Baird et al., 1990), and they cause behavioral abnormalities in feeding (Balakrishnan and Rodrigues, 1991) and grooming behavior (Phillis et al., 1993) and in visual transduction (Homyk et al., 1980). The two transcripts are highly homologous; they have common $3^{\prime}$ ends and are $69 \%$ identical in their unique $5^{\prime}$ regions. The encoded proteins have $M_{\mathrm{r}}$ values of $44 \mathrm{kDa}$, four putative 
transmembrane domains, and cytoplasmically located $\mathrm{N}$ and $\mathrm{C}$ termini (Krishnan et al., 1993; Crompton et al., 1995).

In this report, we extend the functional analysis of the shaking$B$ (neural) transcript, addressing specifically its role in the genesis of electrical synapses in the GFS. We have used an enhancer-trap line to map the development of the GF and intracellular injection of Lucifer yellow to monitor the formation of electrical synapses. The GFs develop during the first third of metamorphosis and have formed functional electrical synapses by mid-pupation. Shaking$\mathrm{B}$ (neural) protein is expressed first by neurons of the GFS around the time of synaptogenesis. Its absence causes a failure to establish functional coupling.

\section{MATERIALS AND METHODS}

\section{Drosophila culture, stocks, and pupal staging}

The wild-type strain used was Oregon-R. shak- $B^{2}$ is an ethyl methanesulfonate (EMS)-induced mutation at the shaking- $B$ locus, originally isolated in a screen for behavioral mutants (Homyk et al., 1980). This allele eliminates shaking-B(netural) function. The A.307 enhancer-trap line carries a P-element insertion containing the GAL 4 gene in chromosome 2. The line was generated in a mobilization screen in one of our laboratories (K. Moffat, J. Connolly. J. Kcane, S. Sweeney, and C. O'Kane, unpublished observations). These flies were crossed with a UASlac $Z$ line that has a P-element insertion containing lac $Z$ fused to a GAL4-sensitive $\left(\mathrm{UAS}_{(\mathrm{j}}\right)$ promoter in the X-chromosome (Fischer et al., 1988; Brand and Perrimon. 1993).

Drosophila were raised at $25^{\circ} \mathrm{C}$ using standard procedures. Metamorphosis was staged as follows. Cultures containing third instar (crawling) larvae were cleared of all pupae and then checked at intervals of 5-30 min. White prepupae were transferred (time 0 ) to fresh culture vials and left to develop at $25^{\circ} \mathrm{C}$. Stages, defined as hours after puparium formation (APF), are therefore $+30 \mathrm{~min}$ maximum. At $25^{\circ} \mathrm{C}$, pupation lasts for 93-106 hr. The morphology of pupae at different stages has been described by Bainbridge and Bownes (1981).

\section{Nervous system dissection}

Nervous systems were dissected in cold Drosophila saline $(128 \mathrm{~mm} \mathrm{NaCl}$, $2 \mathrm{~mm} \mathrm{KCl}, 4 \mathrm{~mm} \mathrm{MgCl}, 1.8 \mathrm{~mm} \mathrm{CaCl}, 36 \mathrm{~mm}$ sucrose, $5 \mathrm{~mm}$ HEPES, pH 7.1). For X-gal- and immunostaining, whole nervous systems were fixed immediately in the appropriate fixative (see below). For intracellular injection, the cervical connective was desheathed with sharp forceps to expose the axons. The nervous systems were mounted onto poly-L-lysine $[0.01 \%(\mathrm{w} / \mathrm{v})$; Sigma, Poole, UK]-coated glass coverslips in a chamber containing Drosophila saline and transferred to the stage of a Zeiss microscope (Zeiss, Welwyn, Garden City, UK) equipped with fluorescence and water-immersion Nomarski optics.

\section{$\beta$-Galactosidase detection}

Whole-mount nervous systems were fixed in $0.5 \%$ glutaraldchyde in PBS Dulbecco "A" (Unipath, Basingstoke, UK), for $15 \mathrm{~min}$ at room temperature, washed in PBS, and stored for up to $2 \mathrm{~d}$ at $4^{\circ} \mathrm{C}$. X-gal (5-bromo4-chloro-3-indolyl- $\beta$-D-galactopyranoside)-staining solution was prepared as follows: $20 \mu \mathrm{l}$ of $\mathrm{X}$-gal (American Biorganics, Niagara Falls, NY, or Boehringer Mannheim, Lewes, UK; from $100 \mathrm{mg} / \mathrm{ml}$ stock in dimethylformamide stored in the dark at $-20^{\circ} \mathrm{C}$ ) was added slowly to $1 \mathrm{ml}$ of staining buffer $(5 \mathrm{~mm}$ potassium ferricyanide, $5 \mathrm{~mm}$ potassium ferrocyanide, $3 \mathrm{mM} \mathrm{MgCl}, 0.2 \%$ Triton X-100) in PBS, pH 7.4) while mixing at room temperature. The tissuc was incubated in freshly prepared staining solution at $37^{\circ} \mathrm{C}$ for $1 \mathrm{hr}$ to several days, washed in PBS, cleared in a $50-100 \%$ glycerol series, and slide-mounted in $100 \%$ glycerol.

\section{Intracellular injection}

The axons of the GFs in the cervical connective were identified, by their size and position, using a $40 \times$ water-Immersion objective and Nomarski optics. One axon was impaled, under visual control, with a borosilicate glass microelectrode $(40-80 \mathrm{~m} \Omega)$ tip-filled with Lucifer yellow $\left(M_{\mathrm{r}} 457\right.$ $\mathrm{kDa}$; solution $3-4 \%$ in $\mathrm{H}_{2}(0)$, lysinated rhodamine dextran $\left(M_{\mathrm{r}} 10,000\right.$ $\mathrm{kDa} ; 30-50 \mathrm{mg} / \mathrm{ml}$ in $\mathrm{H}_{2}(0)$, lysinated fuorescein dextran $\left(M_{\mathrm{r}} 3000 \mathrm{kDa}\right.$; $50 \mathrm{mg} / \mathrm{ml}$ in $\mathrm{H}_{2}(\mathrm{O}$, all from Cambridge Bioscience. UK). In some cases, a combination of the first two dyes was used. Electrodes were back-filled with $2 \mathrm{M} \mathrm{LiCl}_{2}$ (Lucifer yellow and rhodamine dextran) or $1 \mathrm{M} \mathrm{KCl}$ (fluorescein dextran). Very brief viewing with low-intensity fluorescence was used to verify that the GF had been penetrated successfully. The dyes were injected with hyperpolarizing (Lucifer yellow, fluorescein dextran) or depolarizing (rhodamine dextran) current pulses (5nA) for up to $1 \mathrm{hr}$. Nervous systems then were fixed in $4 \% p$-formaldehyde for $1 \mathrm{hr}$ at room temperature, washed in PBS, dehydrated in ethanol, cleared, and slidemounted in methylsalicylatc.

\section{Immunocytochemistry}

Antibodies. Polyclonal antisera were raised in female Wistar rats to a synthetic peptide corresponding to 14 amino acids from the $\mathrm{C}$ terminus of the shaking-B protein, conjugated via a cysteine residue to maleimideactivated keyhole limpet hemocyanin (Pierce and Warriner, Chester, UK). The sequence of the peptide, including the added cysteine (underlined) was CQHHRVPGLKGEIQD [amino acids 347-360 and 358-371 in the sequence of the neural (Krishnan et al., 1993) and lethal (Crompton et al., 1995) forms of the protein, respectively].

Immunolabeling. Nervous systems were fixed in $4 \% p$-formaldehyde in PBS for $30 \mathrm{~min}$ at room temperature before washing in PBS containing $0.3 \%$ Triton X-100 and preincubation for a minimum of $1 \mathrm{hr}$ at room temperature in blocking solution $[0.1 \%$ Tween-20, $0.2 \%$ bovine serum albumin, and $0.5 \%$ Boehringer blocking reagent (purificd dry milk powder) in PBS]. Shaking-B antisera, diluted 1:500 in blocking solution, were added, and incubation was continued overnight at $4^{\circ} \mathrm{C}$. Whole-mounts were washed in PBS containing $0.1 \%$ Tween-20, incubated for $30 \mathrm{~min}$ in hydrogen peroxide $\left(\mathrm{H}_{2} \mathrm{O}_{2} ; 3 \%\right.$ in PBS), and washed in blocking solution. Peroxidase conjugated anti-rat IgG (Sigma), diluted 1:500 in blocking solution, was added for $2 \mathrm{hr}$ at room temperature. After washing, as before, color was developed with diaminobenzidine (Vectastain kit, Vector, Peterborough, UK; $0.2 \mathrm{mg} / \mathrm{ml}$ in PBS) and $\mathrm{H}_{2} \mathrm{O}_{2}\left(0.015 \%\right.$ in $\left.\mathrm{H}_{2} \mathrm{O}\right)$. Nervous systems were dehydrated in ethanol, cleared in xylenc, and slicte-mounted in Canada Balsam (NBS Biologicals, I Iuntington, UK). No staining was observed when the antisera were preabsorbed with the peptide antigen.

\section{Analysis}

Whole-mounts were viewed and photographed with a Zeiss Axiophot microscope equipped with Nomarski and fluorescence optics. Confocal images of Lucifer yellow-filled preparations were prepared using an argon laser scanning confocal microscope (MRC 600, Bio-Rad, Hemel Hempstead, UK); each picture is the projection of a series of images collected at $2 \mu \mathrm{m}$ steps.

\section{RESULTS}

\section{Enhancer trapping to mark the GFs}

A transgenic $P[G A L 4]$ line, designated A307, shows striking $\beta$-galactosidase ( $\beta$-gal) expression in a pair of large, descending neurons in the adult CNS (Fig. 1). $\beta$-Gal is located in both the nucleus and the cytoplasm and allows the entire morphology of the neuronal processes to be visualized. The cell body (diameter 24-29 $\mu \mathrm{m}$; Fig. 1, arrowhead) is located just below the dorsal protocerebral surface. A thin neurite extends $10-20$ $\mu \mathrm{m}$ posteriorly and ventrally before enlarging to form the dendritic arborization, which comprises one large and two smaller dendrites. The large dendrite loops posterolaterally and ventrally to arborize extensively in the deutocerebrum. One minor dendrite projects dorsomedially, the other ventrolaterally; the former appears to contact the $\beta$-gal-expressing bundle of axons that crosses the midline in the central commissure (see below). The large-diameter $(7-8 \mu \mathrm{m})$ axon of the GF runs posteriorly toward the ventral midline; near the posterior end of the esophageal canal it projects dorsally and exits the brain along the dorsal midline of the cervical connective. It continues without branching through the prothoracic (T1) to the anterior half of the mesothoracic neuromere; the distal tip of the axon then turns sharply and extends $\sim 25-30 \mu \mathrm{m}$ toward the ventrolateral edge of the ganglion (Fig. 1, arrow). The position and size of the cell body, the trajectory of the axon, and the characteristic terminal bend distinguish this cell un- 


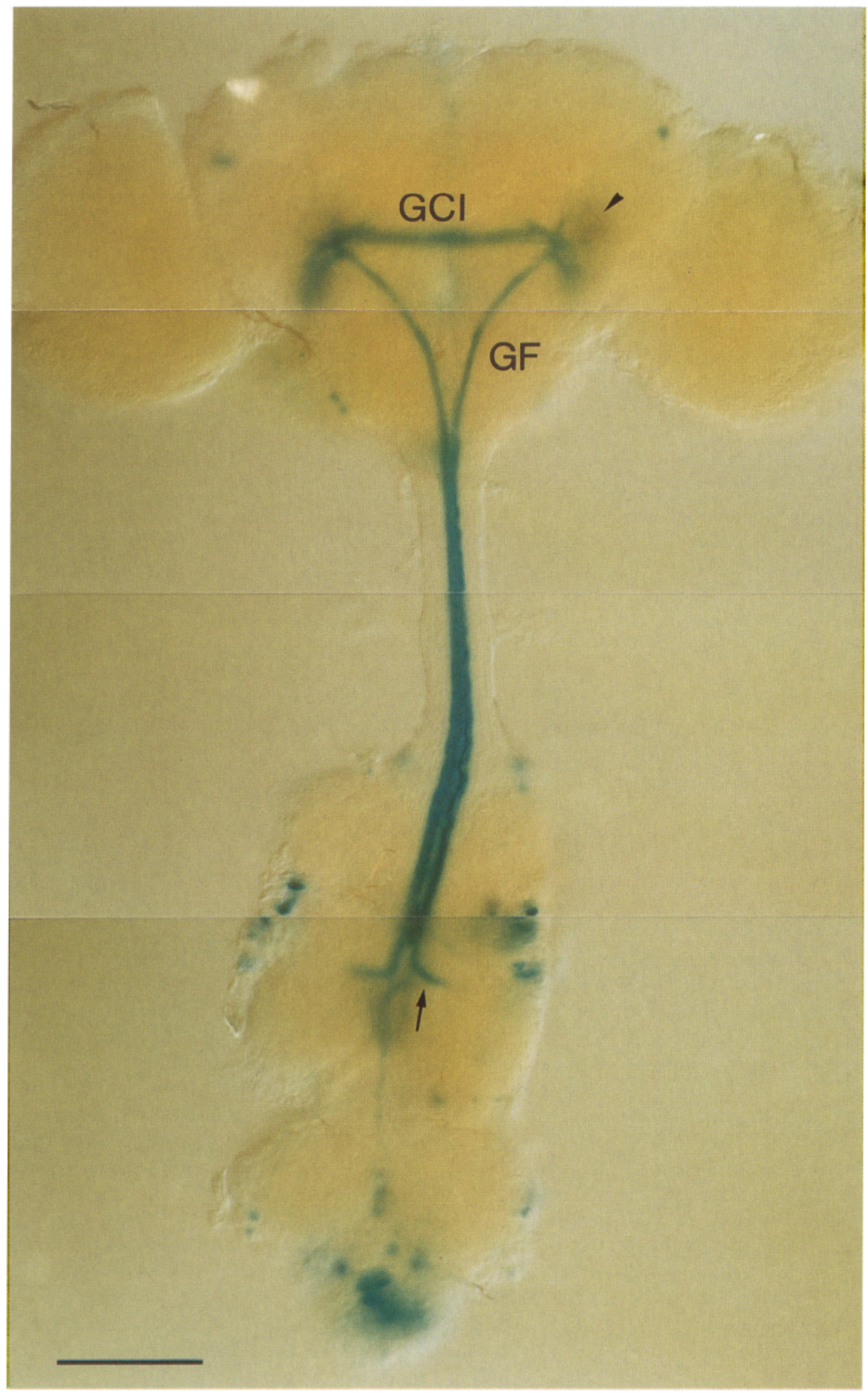

Figure 1. Enhancer-trap line A307 reveals GF anatomy. Dorsal view of an adult nervous system stained for $\beta$-gal activity. The giant fibers $(G F)$ are distinguished by their characteristic morphology. The cell bodies (arrowhead on the right) and dendrites are out of focus; the distal tip of the descending axon bends laterally in the mesothoracic neuromere (arrow). The axons of the giant commissural interneurons $(G C I)$ and small clusters of cells in the thoracic and abdominal neuromeres also are labeled. Scale bar. $100 \mu \mathrm{m}$. equivocally as the GF, originally discovered by Power (1948) and described in more detail by others in Drosophila (Koto et al., 1981) and in larger flies (Bacon and Strausfeld, 1986).

In addition to the pair of GFs, lac $Z$ is expressed in a small number of other cells, most notably the axons of giant commissural interneurons (GCIs) in the brain, and in a bilateral pattern of scattered cells in the brain and thoracic-abdominal ganglion.
We show below that the GF makes synaptic connections with the $\beta$-gal-labeled commissural axons. The identity of the other labeled cell bodies in the CNS has not been determined.

\section{Development of the GFs}

Analysis of larval and pupal nervous systems from the A307 transformant line showed that the $l a c Z$ reporter gene was ex- 
pressed carly enough in the developing GF to reveal the growth of its processes.

\section{$G F$ axonal and dendritic development}

Using the X-gal-staining procedure, the cell bodies of the GFs cannot be distinguished during larval and very early pupal development among other $\beta$-gal-expressing cells in the nervous system. They are first clearly recognizable by their position, their relatively large size, and the trajectory of the growing axon at 6 hr APF (Fig. $2 A$, arrowhead). Axonal extension is already underway, indicating that the neurons are born some time earlier. At $6 \mathrm{hr}$ APF, the axon has grown a distance of $\sim 50 \mu \mathrm{m}$ (5 times the cell body diameter) posteromedially from its origin; the distal tip (Fig. $2 \mathrm{~A}$, anow) is lateral to the anterior region of the esophageal canal. A well defined, splayed growth cone is not visible at this or later stages. We cannot determine with the light microscope whether the growth cone is unremarkable or whether $\beta$-gal, despite its concentration in the distal axon (see below and Fig. $2 A, B$ ) does not enter the growth cone in significant amounts.

At early pupal stages (up to $14 \mathrm{hr}$ APF), we consistently found that the distal regions of the axons were stained more intensely. The period coincides with the time of rapid axon extension (see below), and the speed of axonal transport may prevent accumulation of significant amounts of the enzyme in the proximal region. Regardless of the cause, we feel confident, in view of its concentration distally, that $\beta$-gal labels the leading tip of the growing axon and provides a true measure of axonal length. From its position at $6 \mathrm{hr} \mathrm{APF}$, the axon terminal turns and grows straight along the dorsal midline; between 8 and 9 hr APF (data not shown) it passes through the prothoracic neuromere, and from 10 to $14 \mathrm{hr}$ (Fig. 2B) it is already at the anterior-posterior boundary of the mesothoracic neuromere, the region in which the lateral bend will form. The mean growth rate is initially $50 \mu \mathrm{m} / \mathrm{hr}$ (between 6 and $9 \mathrm{hr}$ APF). It slows dramatically to $3 \mu \mathrm{m} / \mathrm{hr}$ or may pause momentarily between 10 and $14 \mathrm{hr}$ as the neuron approaches its target. The variability in the time taken to reach the target region may be attributed in part to slight discrepancies in pupal stages (see Materials and Methods). There is some genuine variation, however, in the rate of growth; occasionally, the distal lip of one of the bilaterally symmetrical pair of GFs is observed (Fig. $2 B$, arrowhead) to be further posterior than its contralateral homolog.

At 18 hr APF (Fig. 2C), the dendritic arborization of the GFs is clearly visible. The distal tip of the axon deflects from the midline laterally (Fig. 2C, arrowhead) and during the next $12 \mathrm{hr}$ extends the final $\sim 15 \mu \mathrm{m}$ of its axon (Fig. $2 E$ ). Between 18 and 24 $\mathrm{hr}$, while the bend is forming, the GFs are observed consistently to extend for a further $70-100 \mu \mathrm{m}$ along the midline, into the metathoracic neuromere (T3; stained fibers posterior to arrowheads in Fig. $2 D$ ). This region of the axon is retracted soon thereafter; it is not evident in $30 \mathrm{hr}$ pupal nervous systems (Fig. $2 E$ ), by which time the distal bends are fully formed. At $72 \mathrm{hr}$ APF, the GFs have a characteristic adult morphology (compare Figs. 1 and $2 F$ ). The extension of the axon is accompanied by a progressive increase in its diameter. At $24 \mathrm{hr}$ APF (Fig. 2D), it is $\sim 4 \mu \mathrm{m}$ or approximately half its adult diameter, and at $72 \mathrm{hr}$ (Fig. $2 E$ ), it is $5-6 \mu \mathrm{m}$ wide.

\section{lacZ expression in other cells in the A307 line}

In contrast to its relatively specific cxpression in the adult nervous system (Fig. 1), lacZ is widely expressed in neurons of the pupal nervous system. Whereas it is expressed continuously in the de- veloping GFs, the reporter is dynamically expressed in other cells of the CNS as it undergoes the gross morphological changes associated with metamorphosis (Fig. 2). A complete description of reporter gene expression in the enhancer-trap line will be provided in another report (K. Moffat, unpublished data).

\section{Synaptic connectivity in the GFS}

To define and analyze the electrical connections made by the GFs, we injected fluorescent tracers into the GF in the cervical connective. The axon was impaled because the cell body cannot be reliably identified visually in the pupal or adult brain. We demonstrate below that Lucifer yellow $(M, 457 \mathrm{kDa})$ injected into the GF fills several known and previously unidentified neurons in the GFS. We believe that Lucifer yellow-coupled neurons in this system are coupled electrically; we have verified that the pattern is identical to that observed using cobalt (data not shown), which reveals the presence of electrophysiologically defined electrical synapses in the fly GFS (Strausfeld and Bassemir, 1983; Bacon and Strausfeld, 1986).

\section{Electrical connections in the adult GFS: identity of the $G F$-coupled neurons}

Figure $3 A$ is a confocal image of a Lucifer yellow fill of one GF in an adult nervous system. The dye was injected at the indicated position (Fig. $3 A$, large anrow) and has traveled anterogradely and retrogradely to fill the $\mathrm{GF}$ completely. Its morphology is essentially as observed in the X-gal-labeled A307 line (Fig. 1); however, the lateral bend in the mesothoracic neuromere is not visible in the low-power image (Fig. $3 A$ ). A tuft of short medial collaterals (Fig. 3A, small arrow) not resolved by $\mathrm{X}$-gal staining extends from the axon just before it bends. The dye has passed from the GF into several neuronal processes and cell bodies in the brain and thoracic ganglion. Those in the numbered positions (Fig. $3 A, 1-3$ ) are shown at higher magnification (Fig. $3 B-D$ ) and are described in turn below.

We conclude that the cell at position 1 (Fig. $3 A$ ) is the TTMn (shown at high power in Fig. $3 B$ ). Its 10 - to 15 - $\mu$ m-diameter cell body is located in the posterior region of the accessory mesothoracic neuromere at the lateral edge of the ganglion (Power, 1948). The cell body is ventral to the bend of the GF axon. A neurite extends posteriorly, $\sim 25 \mu \mathrm{m}$, and then bifurcates. One branch runs dorsomedially toward and contacts the laterally directed distal tip of the GF; the other continues posteriorly and branches distally at the T2-T3 boundary (Fig. 3B, arrowheads). This anatomy fits the description precisely of the large motoneuron retrogradely filled from the TTM in Drosophila (Baird et al., 1993) and larger flies (Bacon and Strausfeld, 1986). The TTMı axon exits the ganglion in the ipsilateral posterior dorsal mesothoracic nerve (PDMN); it is not visible in Figure $3 B$ but is indicated in Figure $3 C$ (small arrow).

We identify cell 2 (Fig. $3 A$ ) as the PSI (Fig. 3C). Its cell body $(\sim 8 \mu \mathrm{m})$ is located just medial and anterior to the TTMn cell body. A long, thin neurite projects ventrally and medially across the mesothoracic ganglion to contact the GF at the tuft of collaterals (Fig. 3C, downward pointing arrowhead). From there, the axon continues dorsally, as a much larger diameter process, across the midline to exit the ganglion in the contralateral PDMN (Fig. $3 C$, upward pointing arrowhead). The neurons have an extensive dendritic arborization mediolaterally in the ganglion at their region of contact with the GFs (clearly fluorescent in Fig. $3 B$ and weakly in Fig. $3 C$ ). This anatomy has been described by Strausfeld and Bassemir (1983). We invariably stain both PSIs from an 

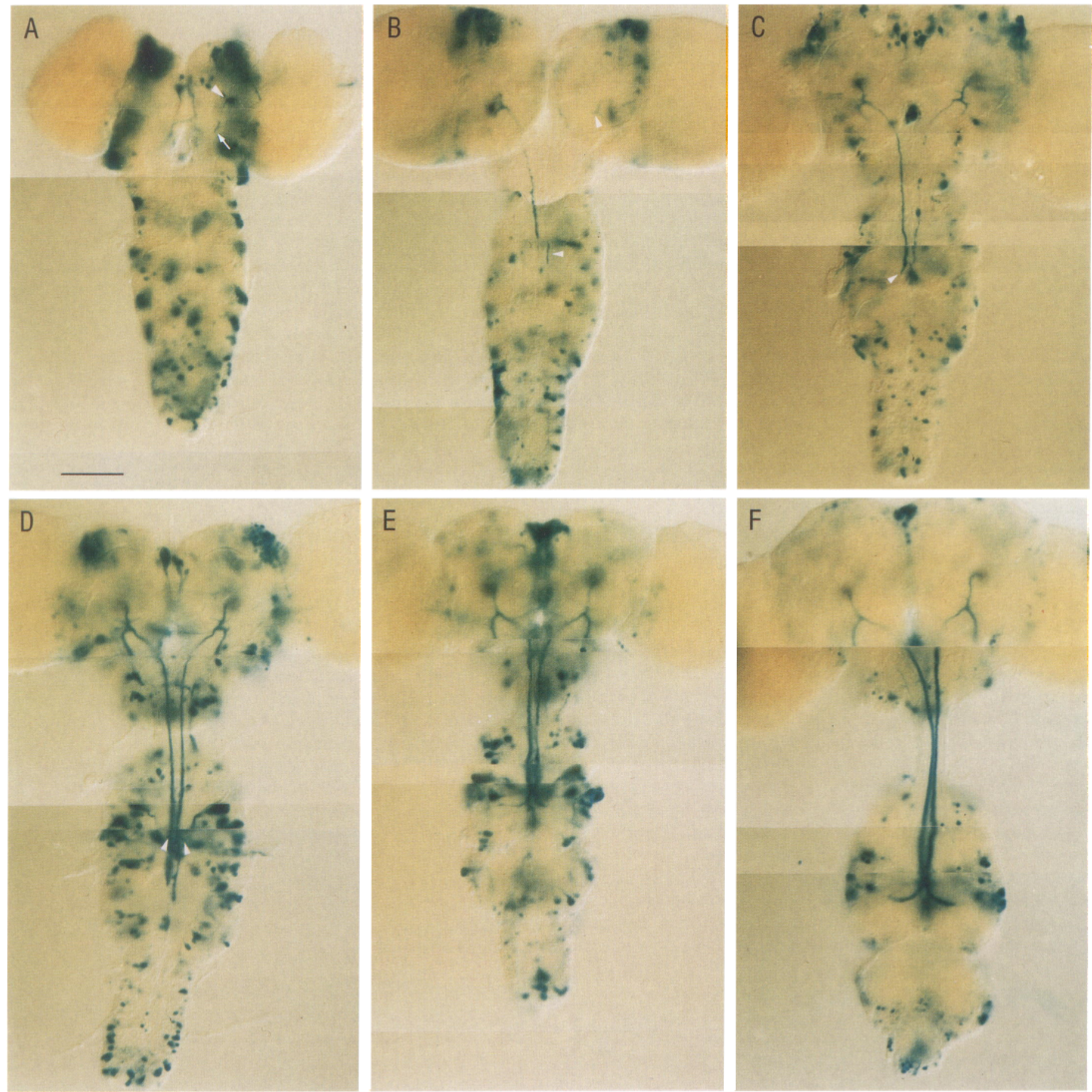

Figure 2. lac $Z$ is expressed early in GF development in enhancer-trap line A307. Dorsal views of pupal nervous systems stained for $\beta$-gal activity at $6(A), 14(B), 18(C), 24(D), 30(E)$, and $72(F)$ hr APF. At $6 \mathrm{hr}(A)$, only one of the pairs of GFs is labeled visibly (arrowhead). The growing tip (arrow) is leaving the protocerebrum. At $14 \mathrm{hr}(B)$, both cell bodies can be seen and the complete morphology of the left GF is visible; its growth cone has reached the posterior region of the prothoracic neuromere. Only the growing tip (arrowhead) of the right GF axon is visible and is already in the mesothoracic neuromere; some dendritic arborization is visible in the brain (arrowhead). At $18 \mathrm{hr}(C)$, the developing GF dendrites are clearly visible and the axons are beginning to bend laterally in the mesothoracic neuromere (arrowhead). At $24 \mathrm{hr}(D)$, the developing bends are labeled (arrowheads) but the axon transiently extends beyond its target domain into the metathoracic neuromere. By $30 \mathrm{hr}(E)$, GF metathoracic processes have retracted and the mesothoracic bends are complete. At $72 \mathrm{hr}(F)$, the GFs have a characteristic adult morphology. Scale bar, 100 $\mu \mathrm{m}$ (shown in $A$ ). 
injection into a single GF; this indicates, as the anatomy predicts, that each PSI synapses with both GFs and/or with one another.

In the brain, the GF is dye-coupled to a prominent group of fasciculating processes ( 3 in Fig. $3 A$ ) that are located slightly ventral to the GFs and cross the central commissure (Fig. $3 D$, black arrows). Based on their position and size, it is likely that these are the same giant interneurons that express $\beta$-gal in the A307 line (Fig. 1). The axons appear to be connected by fine posterior-directed neurites to small dorsal cell bodies in the latcral protoce rebrum (Fig. 3D, white arrows). A Lucifer yellow fill of one GF causes the preferential labeling of the contralateral cell body cluster and three axons. Additional, more weakly labeled axons invariably are visible (Fig. $3 D$, black arrow at the midline), and the ipsilateral cluster of cell bodies can be distinguished in some preparations (not visible in Fig. $3 D$ ). This pattern of dye transfer and the anatomical arrangement of the neurons suggest that each trio of commissural neurons synapscs with both right and left GFs and/or with the contralateral trio. In the first instance, the axon terminals of the GCIs may synapse with the dorsomedial and, possibly, the large deutocerebral dendrite and axon (at their junction) of the contralateral GF, whereas the dendrites (of the same commissural neurons) synapse with the dendrites of the ipsilateral GF.

Prolonged intracellular filling of one GF frequently causes transfer of the dye to its contralateral homolog. We reasoned, based on the above considerations, that the synaptic connection is mediated, at least in part, by the commissural axons. To localize sites of communication between the GF homologs directly, we gently crushed either the central commissure or the anterior cervical connective before injecting Lucifer yellow into one GF Both procedures reduced, but did not eliminate, the passage of dye into the contralateral neuron (data not shown). This indicates that the GFs synapse in the brain via the commissural neurons and, additionally, in the thoracic ganglion, presumably at the tuft of collaterals in the mesothoracic neuromere, where they are known to make physical contact (King and Wyman, 1980).

We have not established the identity of the additional labeled processes observed in the thoracic ganglion (Fig. 3A). Some of these cells may be interneurons with cell bodies forming the weakly fluorescent cluster, seen in Figure $3 C$, neighboring the cell body of the PSI. Others may be the axons of wing and leg sensory ncurons that project from the periphery. It is not clear whether they are coupled directly to the GFs or secondarily to the TTMn and/or the PSI.

We dye-filled $>50$ GFs and invariably observed coupling to the neurons in the brain and thoracic ganglion after injection periods of 2 () min or longer. During shorter filling periods, Lucifer yellow commonly transfers to the GCls but not necessarily to the thoracic ganglion neurons.

\section{Development of electrical connections}

The morphological development of the GFs is complete at $\sim 30 \mathrm{hr}$ APF (see above and Fig. 2). Although ideally one would like to begin a developmental study of Lucifer yellow coupling at this stage, we could not impale the axon successfully earlier than $45 \mathrm{hr}$ APF. The size of younger axons precludes their visual identification and injection as a single cell in the cervical connective.

At 45 hr APF, injection of Lucifer yellow into the GF labels the neuron itself and a single cell located at the ipsilateral margin of the mesothoracic neuromere (Fig. $4 A$, arrowhead). Processes of the coupled cell, including that which contacts the GF, are not visible, presumably because of their small size. A weakly fluorescent cell in the same position is observed, at $48 \mathrm{hr}$ APF (Fig. $4 B$, leftward pointing arrowhead) and more clearly at later stages, to have a process that extends medially to the distal bend of the GF (Fig. $4 B$, upward pointing arrowhead). Based on its morphology and cell body position, we identify this cell as the TTMn (see Fig. $3 B$ ). Also coupled to the GF at $48 \mathrm{hr}$ APF is a pair of bilaterally symmetrical mesothoracic neurons with cell bodies located just anterior and medial to the TTMn and neurites that contact the GF at the midline (Fig. 4B). Symmetrical filling of the neurons, together with the projection of the axon, indicates that these are the PSIs (see Fig. 3C).

In some well filled $55 \mathrm{hr}$ pupae, a cluster of small, weakly fluorescent cells in the contralateral (with respect to the filled GF) lower protocerebrum can be just visualized (data not shown). At $65 \mathrm{hr}$, the same cells (out of focus in Fig. 4C, black arrowhead) are clearly visible and are connected by fine neurites to axons that cross the central commissure. These are clearly the commissural neurons described in the adult (see Fig. $3 D$ ).

The GF, therefore, has formed electrical synapses with the ipsilateral TTMn, hoth PSIs and the GCIs by $5.5 \mathrm{hr}$ APF. The overall pattern of coupling does not change between $65 \mathrm{hr}$ (Fig. $4 C$ ) and $95 \mathrm{hr}$ (Fig. 4D) APF. The period is characterized by a general enlargement of the GF and the coupled neurons. Dye transfer to the presumptive interneurons/sensory neurons in the thoracic ganglion is not observed during pupal development. Coupling via these electrical synapses is evident first in the newly emerged adult.

\section{Characterization of the synaptic junctions}

The transfer of a dye from one neuron to another presumably is a function of the pore size, density, and charge properties of the cellular junction. Gap junctions vary in size; the largest in insects

\footnotetext{
Figure 3. Lucifer ycllow injection into the adult GF reveals a functional asscmbly of coupled neurons. Confocal microscopy of Lucifer ycllow fluorescence. Images were constructed by stacking optical sections taken at $2 \mu \mathrm{m}$ steps in whole-mount nervous systems. $A$, Low-magnification reconstruction of the whole nervous system. The small arrow points to a tuft of medial collaterals that extends from the GF axons just before they bend in the mesothoracic neuromere. The bend is not visible. The lange arrow indicates the site of intracellular injection. The contralateral GF and several other neurons in the brain and thoracic ganglion are labeled by dye transfer. Numbers $1-3$ denote the positions of the individual dye-coupled neurons shown in $B-D$, respectively. $B-D$. Higher-magnification reconstructions of dye-coupled neurons. Arrows in $B$ and $C$ indieate the axon of the GF bending laterally in the mesothoracic neuromere. The coupled cell in $B$ is the TTM motoneuron; arrowheads point to the posterior and medial neurites. The TTMn axon is not visible in $B$ but is indicated in $C$ by a small arrow. The intensely fluorescent, bilaterally symmetrical neurons in $C$ are the PSIs. The ipsi- and contralateral (thicker) portions of the axon on the filled side are indicated by downward and upward pointing arrowheads, respectively. The PSI dendrites arborize extensively along the midline; they are weakly fluorescent in $C$ but clearly visible in $B$. $D$. The cell body $(G F)$ and proximal portion of the axon (arrow/lewd) of the filled GF are shown. The dye-coupled GCIs cross the central commissure. Three axons can be distinguished clearly (black arrows): their cell bodies (small white arrows) are located contralateral to the injected GF. Another weakly labeled axon also is indicated (black arow at the midline). The terminals of the GCIs contact the contralateral GF. Their dendrites arborize in the same region as the dendritic tree of the ipsilateral GFs. Scale bars: $A, 100 \mu \mathrm{m} ; B-D, 25 \mu \mathrm{m} ; C$ as for $B$.
} 

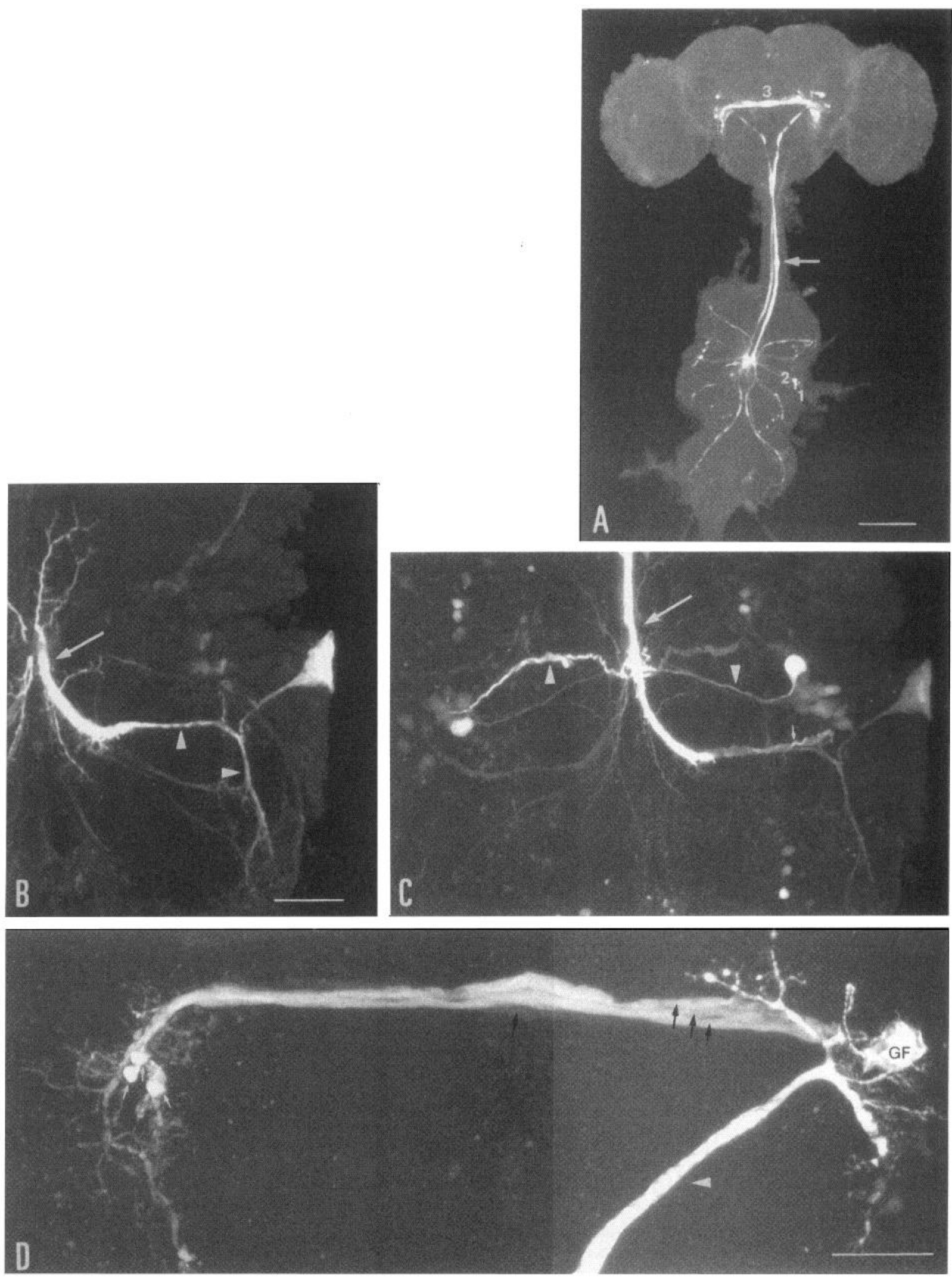

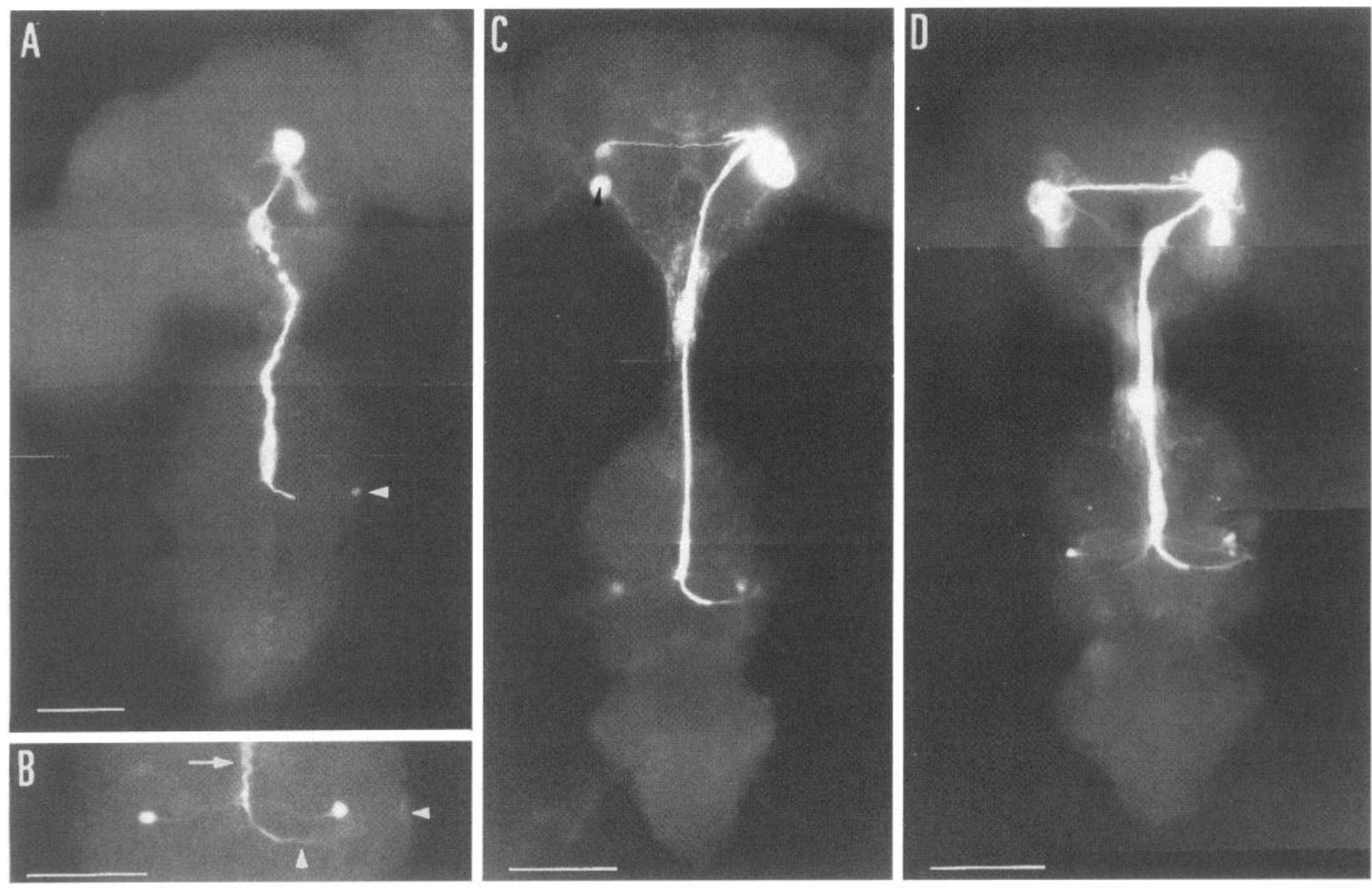

Figure 4. The GF dye-couples to other neurons during metamorphosis. Fluorescence micrographs showing dorsal views of pupal nervous systems in which Lucifer yellow was injected intracellularly into the right GF. A, At $45 \mathrm{hr}$ APF, the GF is dye-coupled to the TTMn (arrowhead) at the lateral margin of the mesothoracic neuromere. TTMn processes are not visible. B. At $48 \mathrm{hr}$ APF, the GF axon, bending laterally in the mesothoracic neuromere, is indicated by an arrow. The bilaterally symmetrical coupled neurons are the PSIs. Posterior to these, part of the medial neurite of the TTMn is shown (upward pointing arrowhead) contacting the distal region of the GF axon. The TTMn cell body is faintly labeled and out of focus (leftward pointing arrowhead). C, At $65 \mathrm{hr}$ APF, in the brain the GCIs are dye-coupled. Their clustered cell bodies (black arrowhead) are out of focus. D, At 95 hr APF, the pattern of GF dye-coupling in the brain and thoracic ganglion is as observed at $65 \mathrm{hr}$ APF. The axonal diameters of the GFs and GCIs are notably larger. Scale bars: $A, B, 50 \mu \mathrm{m} ; C, D, 100 \mu \mathrm{m}$.

are permeant to molecules up to $2500-3000 \mathrm{kDa}$ (Schwarzman et al., 1981). To get some indication of the size of the GFS synaptic gap junctions, we injected fluorescent dextrans of increasing $M_{\mathrm{r}}$ into the adult GF. Fluorescein dextran, $M_{\mathrm{r}} 3000 \mathrm{kDa}$ (Fig. $5 A$ ), labels the axons of the central commissure but not the PSI or TTMn neurons. An $M_{\mathrm{r}} 10,000 \mathrm{kDa}$ rhodamine-conjugated dextran is confined to the GF (Fig. 5B). Rhodamine dextran was injected simultaneously with Lucifer yellow (Fig. $5 C$ ) for comparison and as a control to demonstrate that the gap junctions are functional.

\section{Absence of coupling in shaking-B(neural) mutants}

shak- $B^{2}$ is a genetically null mutation (Baird et al., 1990). Substitution of $\mathrm{A}$ for $\mathrm{T}$ at position 379 of the neural transcript introduces a stop codon so that functional protein is not translated (Krishnan et al., 1993). To determine whether the shaking-B protein is required for dye coupling at some or all of the GFS electrical synapses, we injected Lucifer yellow into the GF of an adult shak- $B^{2}$ fly. The dye labels the GF exclusively (Fig. 6). Despite extensive filling periods in $>20$ flies, we never observed fluorescence in any of the neurons to which the GF is reliably coupled in wild-type flies (described above; see Fig. 3). The pattern of labeling in the mutant (Fig. 6) is identical to that observed with the high- $M_{\mathrm{r}}$, gap junction-impermeant dye in the wild-type fly (Fig. $5 B$ ). Intracellularly injected cobalt also is confined to the GF in shak-B $B^{2}$ mutants (data not shown), which strongly suggests that the Lucifer yellow-uncoupled neurons are electrically uncoupled. Failure to make functional connections cannot be attributed to abnormal GF morphology; in all cases, it appears to be identical to that in wild-type flies (compare Fig. 6 with Figs. 1, 3-5).

\section{Distribution of shaking-B protein in the developing GFS}

We labeled whole-mount nervous systems with shaking-B antisera. These antisera were raised against a peptide corresponding to a region in the $\mathrm{C}$ terminus that is common to neural and lethal forms of the protein (Crompton et al., 1995) and, therefore, are expected to detect both. In situ hybridization studies demonstrate that both transcripts are expressed in the pupal nervous system (Crompton et al., 1995). Comparing the distribution pattern in wild-type and mutant flies (see below), we distinguish neural protein as that which is absent in shak- $B^{2}$.

Immunoreactivity is first detectable in the nervous system at $\sim 20 \mathrm{hr}$ APF. There is uniform low labeling of virtually the entire neuropil of the brain and thoracic ganglia (data not shown). There 

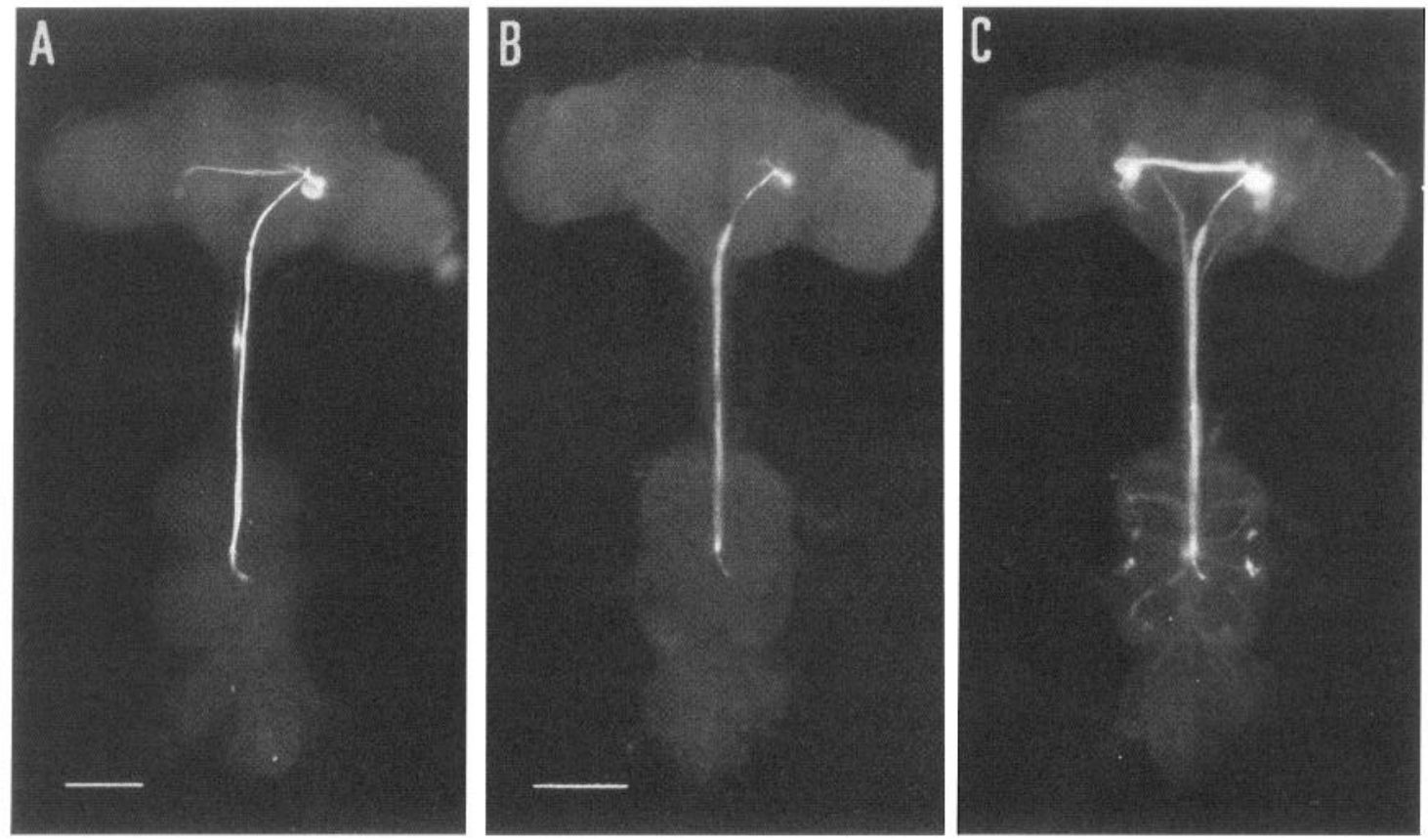

Figure 5. The permeability of the GFS synapses varies. Fluorescence photomicrographs showing dorsal views of adult nervous systems after intracellular injection of the following: fluorescein dextran alone, $M_{\mathrm{r}} 3000 \mathrm{kDa}(A)$; rhodamine dextran, $M_{\mathrm{r}} 10,000 \mathrm{kDa}(B)$ and simultaneously Lucifer yellow, $M_{\mathrm{r}} 457$ $\mathrm{kDa}(C)$. Lucifer yellow transfers to the GCIs in the brain, the TTMn, PSIs, and presumptive interneurons/sensory neurons in the thoracic ganglion $(C$; see also Fig. 4). All of the synapses are impermeable to the $10,000 \mathrm{kDa}$ dye $(B)$, but the GF-GCI synapses pass the $3000 \mathrm{kDa}$ dextran $(A)$. Scale bars: $100 \mu \mathrm{m} ; C$ as for $B$.

appears to be less, but nonetheless detectable, expression in shak- $B^{2}$ mutants compared with wild-type, suggesting that both neural and lethal proteins contribute to the pattern at this time.

At $\sim 30 \mathrm{hr}$ APF, this background is superimposed by more intense staining discretely localized in the mesothoracic neuropil. At this time, the staining is too weak to photograph. The pattern is shown from $40 \mathrm{hr}$ APF (Fig. $7 B-D$ ). There is a symmetrical array of four clusters of staining, an anterior pair and a second pair posterior and slightly medial to the first (Fig. 7B, arrows). From this point, a nonuniformly stained process is delineated that curves posteriorly and laterally and continues for some distance toward the lateral margin (Fig. $7 B$, arrowheads). The profile bears striking resemblance to the terminal bend of the GF and is located precisely where the GF contacts the distal region of the medial dendrite of the TTMn (see Fig. 3B). The anterior cluster is located where the axons of the PSIs cross the GFs (see Fig. 3C). We have confirmed these locations by injecting Lucifer yellow into the GF before labeling with the shaking-B antibody (data not shown). The characteristic pattern of shaking-B antibody staining in the mesothoracic neuromere intensifies as development proceeds (60 hr APF; Fig. 7C), and expression is maintained at high levels in the adult (Fig. $7 D$ ).

Apart from the low uniform neuropil staining (see above), we observe no expression in the brain of $40 \mathrm{hr}$ pupae. At $50-60 \mathrm{hr}(60$ hr APF; Fig. $7 F$ ), a broad cluster of punctate immunoreactivity is evident in the neuropil of the deutocerebrum (Fig. $7 F$, star). This is more intense at later pupal stages and in the adult (Fig. $7 G$ ). Lateral to this, at the plane of focus shown in Figure $7 G$, an anteromedial process is stained. An additional, shorter, narrower process just anterior to the lateral part of the central commissure is particularly heavily labeled (Fig. $7 G$, arrowheads). The morphology of these processes resembles the main and dorsomedial den- drites of the GF, respectively (see Fig. 3D). Lucifer yellow filling of the GF before antibody labeling confirms that the staining localizes to the region where the dendrites of the GFs and GCIs arborize (data not shown).

With the exception of the most anterior of the clusters of immunoreactivity in the mesothoracic neuromere (in the region of the GF-PSI synapse), there is no corresponding staining in shak- $B^{2}$ mutants in either the brain or thoracic-abdominal ganglion (Fig. $7 E$ ). Apart from this, the staining patterns shown in Figure 7 , therefore, reflect the expression of shaking-B(neural) protein. We presume that the staining that persists in the mutant is attributable to the presence of lethal or other forms of the protein; this suggests that different forms of shaking-B are coexpressed at one of the GFS synapses.

We have focused on describing the antibody labeling that we believe is associated with the GFS neurons. However, in addition to that shown in Figure 7, there is prominent immunoreactivity (not present in $s h a k-B^{2}$ mutants) dorsal and lateral to the presumptive GF-TTMn contact from $40 \mathrm{hr}$ APF onward. In late pupae and adults, intensely stained fibers run from $\mathrm{T} 2$, anteriorly and posteriorly into the pro- and metathoracic neuromeres. These may be associated with the presumptive interneurons/sensory neurons that dye-couple to the GFs in the newly emerged adult (see Fig. $3 A$ ). Immunoreactivity also is observed in other regions of the nervous system, including the developing optic lobes. A complete description of the expression of shaking-B proteins is beyond the scope of this article and will be provided in another report (M. Wilkin and J. Davies, unpublished data).

\section{DISCUSSION}

The first part of this study describes GF development and synaptogenesis which have not been documented previously. The sec- 


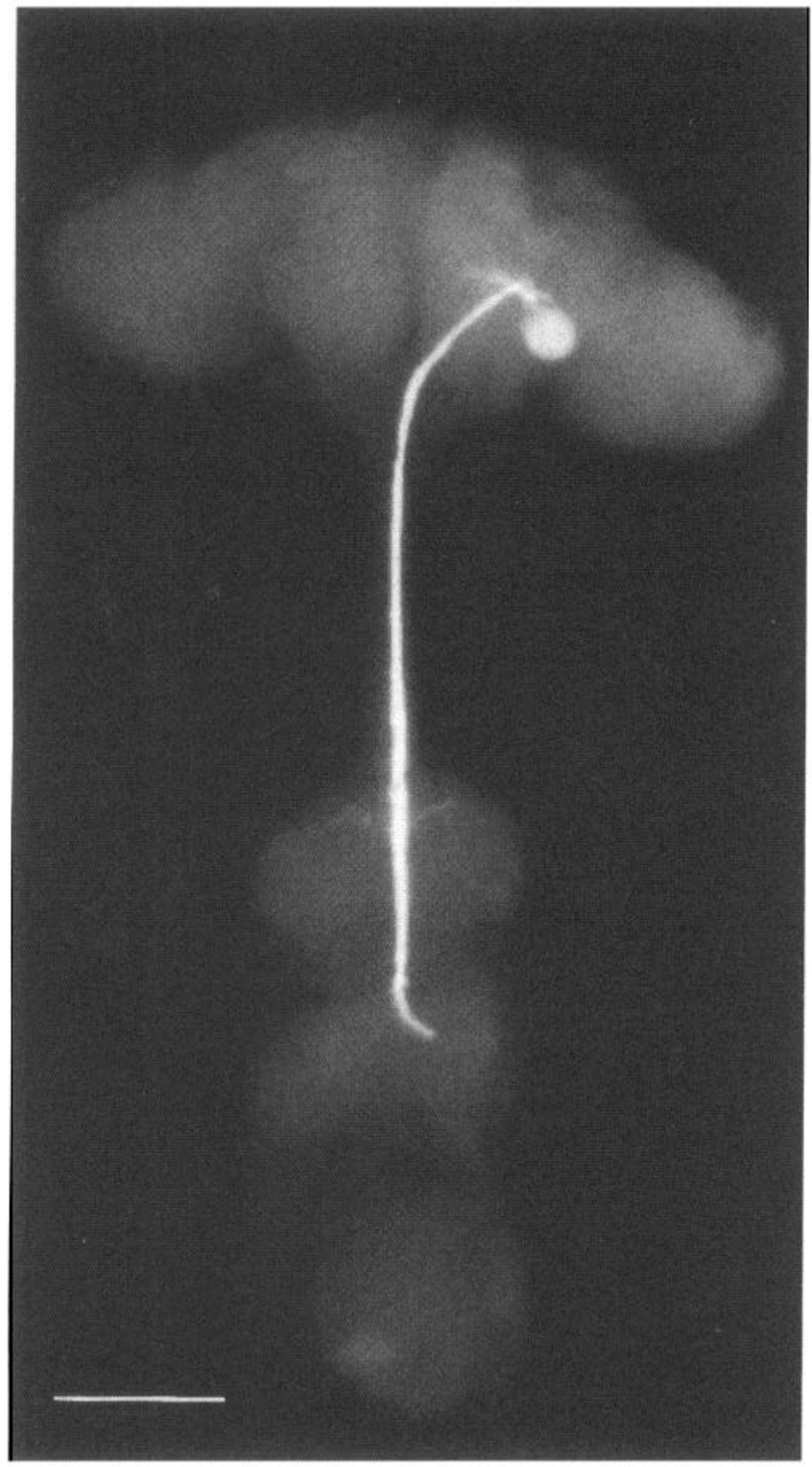

Figure 6. shak- $B^{2}$ mutants exhibit no dye coupling in the GFS. Fluorescence photomicrograph of a dorsal view of the nervous system of an adult shak $-B^{2}$ mutant. Lucifer yellow was injected intracellularly into the GF axon; the dye remains within the GF (compare with Figs. 4, $5 C$ showing wild-type). Scale bar, $100 \mu \mathrm{m}$.

ond part demonstrates that the expression of shaking-B(neural) protein coincides with, and is essential for, the establishment of functional electrical (gap-junctional) synapses.

\section{The GFs develop during metamorphosis}

Using X-gal staining, we first visualized the developing GFs at $6 \mathrm{hr}$ APF. However, in flies raised at a higher temperature $\left(29 \mathrm{vs} 25^{\circ} \mathrm{C}\right.$ in the present study) and labeled with a $\beta$-gal antibody to enhance lac $Z$ expression and intensify the signal, the cell bodies were visible in $\sim 50 \%$ of third-instar larvae (K. Moffat, unpublished data). We cannot predict from these studies when the GF is born. There is no evidence to suggest that the GFs are persistent larval neurons that arise during embryogenesis and are remodeled during pupation. Their axons and dendrites appear to be growing de novo from the late larval stage. Cells with embryonic birth dates were shown to be located primarily in the medial region of the esophageal ganglia and in the pars intracerebralis in pupae and adults (White and Kankel, 1978). Neither location is consistent with the known position of the GF cell bodies. It seems likely that these neurons are born postembryonically. This second wave of neurogenesis begins during the first larval instar and continues until 20-30 hr APF (Truman and Bate, 1988; Ito and Hotta, 1992). In the study of Ito and Hotta (1992), proliferating cells in the region of the GF cell bodies were evident from the early third larval instar to just after puparium formation. Analysis of the spatiotemporal aspects of proliferation indicated that the neurons are generated in a deep-to-superficial gradient (White and Kankel, 1978). The GFs, with cell bodies located close to the dorsal surface of the brain, may be expected then to arise relatively late during this period. Independent experiments in which $\left[{ }^{3} \mathrm{H}\right]$ bromodeoxyuridine is administered to flies are required to determine GF day of birth accurately.

The growth cones of the GFs reach their target area at 10-14 hr APF and shortly thereafter (18-24 hr APF) extend laterally to form the characteristic bends. It is of interest to speculate that the TTMn provides a target-derived cue for lateral turning of the axon. During the period of bend formation, we observed transient overgrowth of the GF axon beyond its target domain into the metathoracic neuromere. We cannot exclude the possibility that this is attributable to a subtle mutation induced by ectopic gene expression in the A307 line. It is remarkably similar, however, to the growth and subsequent pruning of inappropriate processes of embryonic motoneurons that have been described in Drosophila, locust, and leech (Baptista and Macagno, 1988; Myers et al., 1990; Sink and Whitington, 1991a). In these cases, the exuberant processes are withdrawn once the appropriate synapses have formed but persist if the targets are removed (Baptista and Macagno, 1988; Sink and Whitington, 1991b). The retraction of the metathoracic processes of the GFs coincides relatively well with the period of GF-TTMn synapse formation (see below) and, as has been proposed for other systems (Sink and Whitington, 1991b), may be triggered by contact between the pre- and postsynaptic neurons or stabilization of the synaptic connection.

Figure 7. Expression of shaking-B(neural) protein by neurons of the GFS coincides temporally with synaptogenesis. Photomicrographs of selected regions of pupal and adult whole-mount nervous systems labeled with shaking-B peptide antisera. $A$, Schematic diagram of the nervous system illustrating the approximate locations of the regions of neuropil shown in $B-G . B-D$, The mesothoracic neuromere of wild-type at $40 \mathrm{hr}$ APF $(B), 60 \mathrm{hr}$ APF $(C)$, and adult $(D)$. The anterior clusters of immunoreactivity (arrows in $B$ ) on either side of the midline are located where the axons of the PSIs contact the GF axons. The more posterior laterally curving tract (arrowheads in $B$ ) is at the region of apposition between the bend of the GF and the medial dendrite of the TTMn (see also Fig. 3B,C). Labeling intensifies as development proceeds $(B-D)$. There is no corresponding immunoreactivity in shak- $B^{2}$ mutants $(E$; at $60 \mathrm{hr}$ APF), with the exception of two discrete spots in the region of the anterior clusters. This indicates that the labeling shown in $B-D$ reflects the presence of shaking-B(neural) protein. $F, G$, The brain at $60 \mathrm{hr} \operatorname{APF}(F)$ and adult $(G)$. Punctate immunoreactivity is localized in the neuropil of the deutocerebrum (stars in $F$ and $G$ ), where the dendrites of the GFs and GCIs arborize. The labeled processes delineated in $G$ (arrowheads) are probably GF dendrites. No corresponding expression is observed in the brain of shak- $B^{2}$ mutants at any stage. The background neuropil staining observed in $B-G$ is not nonspecific, but it represents weak expression of non-neural forms of the shaking-B protein that also are recognized by the antibody used (see Results). Scale bar (shown in $B$ ): $B-E, G, 20 \mu \mathrm{m} ; F, 50 \mu \mathrm{m}$. 


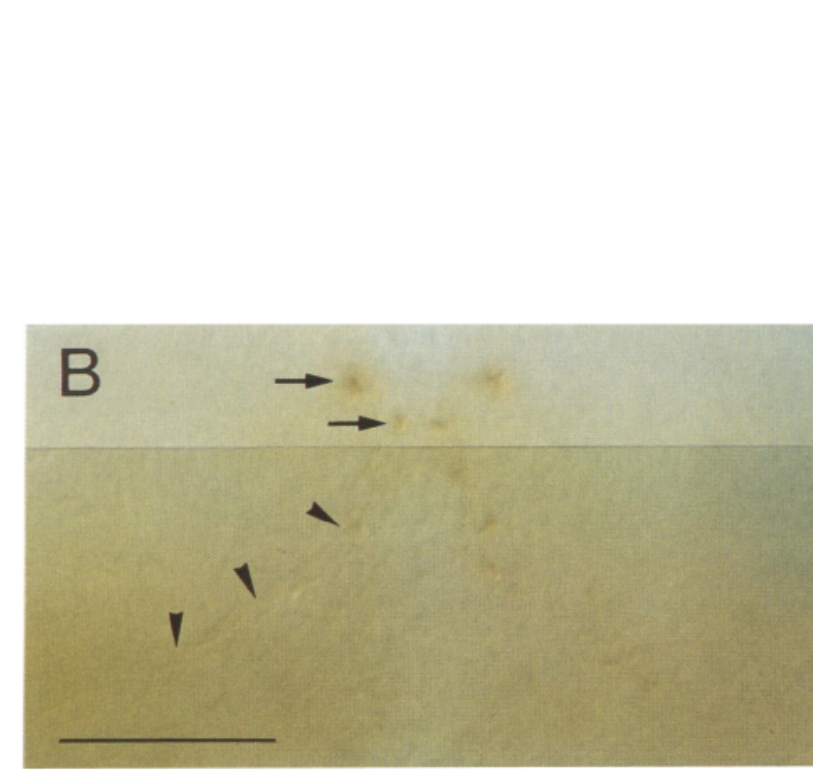

A
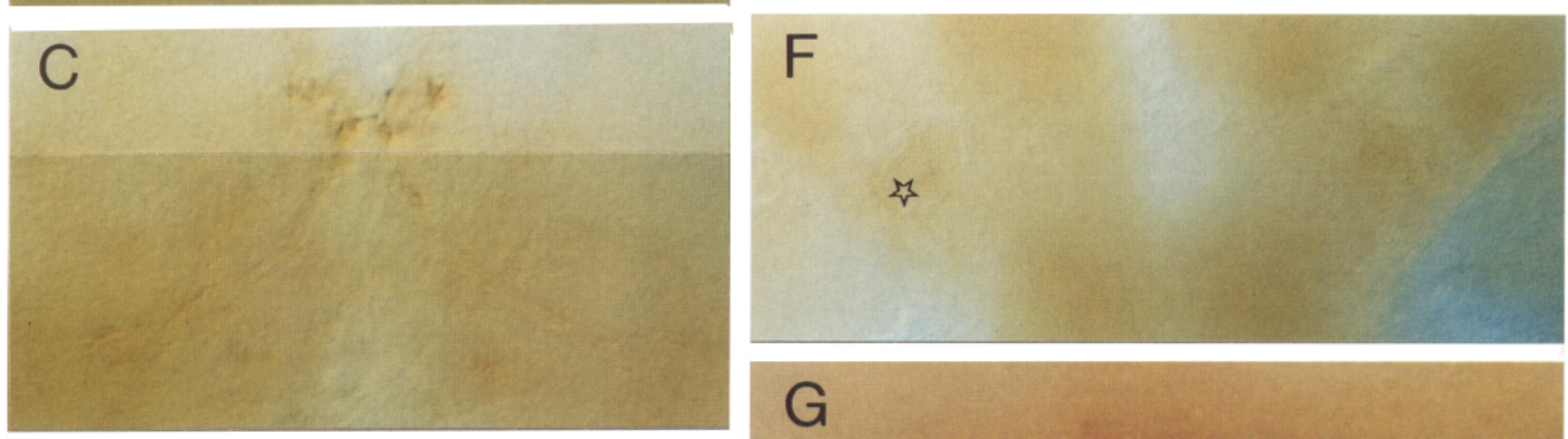

G
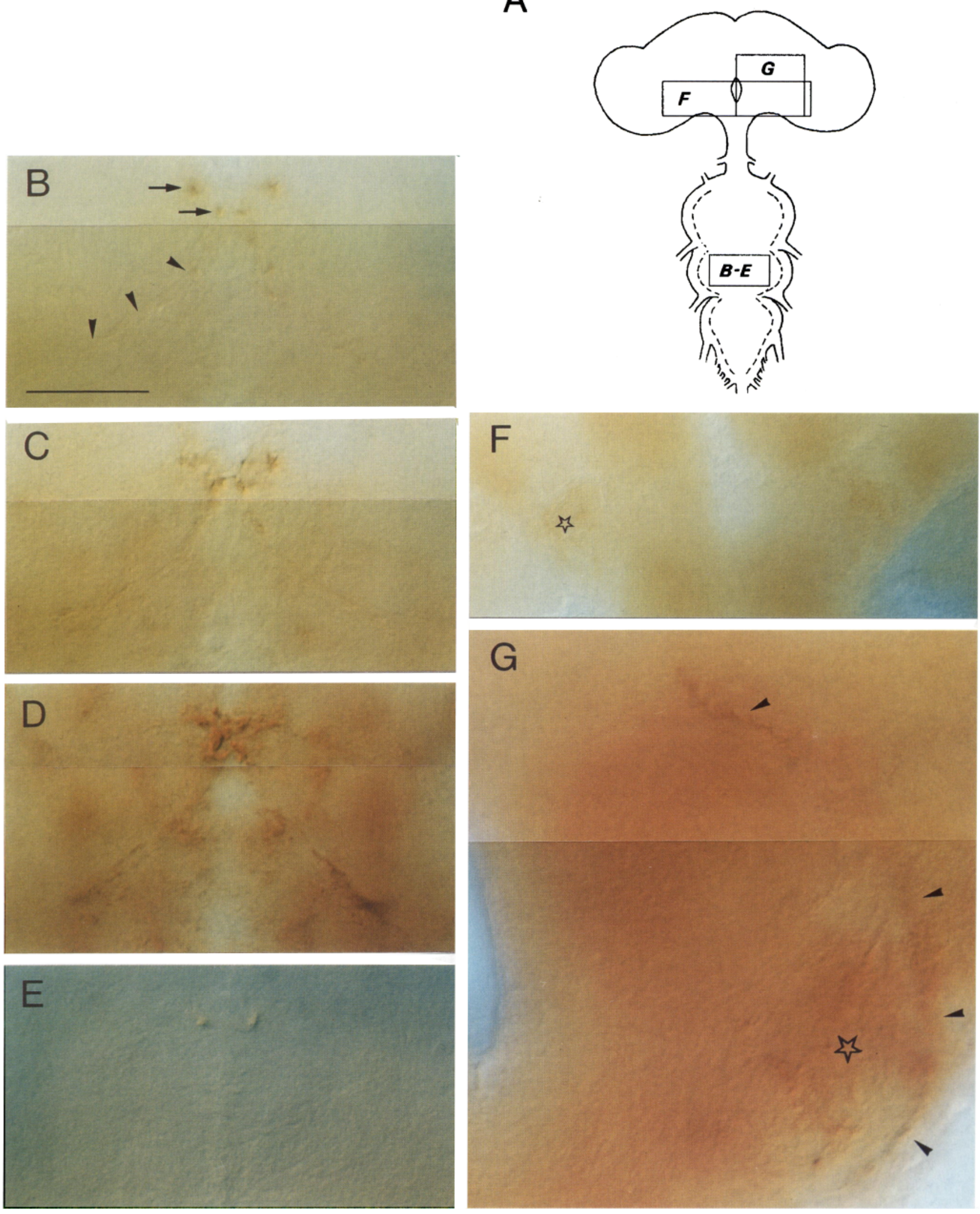
The GFs form electrical synapses with the TTMn, PSI, and $\mathrm{GCls}$ between 30 and $60 \mathrm{hr}$ APF

Previous dye-filling and physiological studies of the GFS in Drosophila, Calliphora, and Musca demonstrated that the synapses made between the GF and the TTMn and PSI neurons are electrical (Tanouye and Wyman, 1980; Strausfeld and Bassemir, 1983; Bacon and Strausfeld, 1986). This is confirmed by our dye-coupling analysis.

We demonstrate that, in Drosophila, the GF also forms electrical synapses with a number of other neurons. The most prominent of these are giant interneurons that cross the brain in the central commissure. In a previous study, Koto et al. (1981) visualized at least one of these neurons by Lucifer yellow injection into the GF. They assumed that it was a contralateral branch of the GF. The confocal images presented in Figure 3 and the observation that these neurons do not label in dye fills of the GF in shak-B ${ }^{2}$ mutants clearly indicate that they are separate, electrically coupled neurons.

The GF forms synapses with the TTMn between 30 and $45 \mathrm{hr}$ APF, with the PSI at $48 \mathrm{hr}$, with the GCIs at $\sim 55 \mathrm{hr}$ and, finally, in the late pupa or young adult the GF electrically couples to the thoracic ganglion interneurons/sensory neurons. At present, there are no markers with which to trace the development of the neurons coupled to the GF, and their cell bodies are not amenable to intracellular filling. Therefore, we do not know precisely when the processes of these neurons first contact the GFs. Studies in the shibire mutant provide indirect evidence suggesting that the TTMn is a persistent larval motoneuron while the PSIs develop during the first third of pupation (Raper Hummon and Costello, 1987). The sequence of synapse formation, therefore, may reflect the temporal development of the coupled neurons.

\section{Shaking-B(neural) protein is located at electrical synapses and is essential for their formation}

Our dye-coupling studies in shak-B $B^{2}$ mutants demonstrate that, although the GF develops an normal adult morphology, it fails to couple to any of its identified targets. This confirms and extends the original observations of Thomas and Wyman (1984). They demonstrated electrophysiologically that the shak $-B^{\text {Pas }}$ mutation, which leads to the production of nonfunctional neural protein (Baird et al., 1990), disrupts synaptic transmission between the GF and the TTM and DLM motoneurons. The studies could not distinguish which of the synapses in the latter disynaptic pathway were affected. Lucifer yellow injection demonstrates that the GF-PSI connection is certainly nonfunctional. This technique cannot identify defects at the PSI-DLMn synapse, which is chemical. Given that all of the electrical (this study) and none of the other chemical (Thomas and Wyman, 1984) synapses are affected, we predict that the PSI-DLMn synapse will develop normally in the mutant.

We have not verified the presence or examined the morphology of the neurons coupled to the GFs in shaking- $B$ mutants. Baird et al. (1993) found that although the medial TTMn neurite did not extend as far along the GF as in wild-type, there remained, nonetheless, an extensive region of apposition between the two neurons. Synaptogenesis in the mutant, therefore, is not precluded on anatomical grounds. At present, it is not possible to visualize the PSIs or GCIs in the mutant nervous system. However, there appears to be no reason to implicate shaking-B(neural) in growth and pathfinding of the GFS neurons.

The appearance of shaking-B(neural) protein at presumptive GFS synaptic terminals coincides with the completion of axonal growth of the GF. Although it is, therefore, expressed at an appropriate time to behave as a recognition molecule, as has been speculated (Krishnan et al., 1993; Haydon and Drapeau, 1995), the overall pattern makes this idea less plausible. Significant expression is not observed until $\sim 40 \mathrm{hr}$ APF, when synaptogenesis is underway, and the protein continues to be expressed at high levels in the adult CNS. One would expect a protein of which the sole function is to mediate pre- to postsynaptic cell recognition to be expressed maximally and transiently just before synapse formation (Halpern et al., 1991).

The available evidence points more toward a role for shaking-B in the formation and continued functioning of electrical synapses. We believe that the immunoreactivity observed with shaking-B antibodies is located at sites of synaptic contact. The punctate nature of the staining (and the assumption that shaking- $B$ is a transmembrane protein) suggests that the protein is associated with distinct structures in the membranc. Electron microscopy is required to confirm that these are the gap junctions between the pre- and postsynaptic membranes.

\section{Does shaking-B(neural) encode a gap-junctional protein?}

shaking-B(neural) clearly participates in the formation of the gap junctions at electrical synapses. Perhaps the simplest interpretation of the data we present here is that the gene product encodes an essential channel protein. Alternatively, it may be involved in the assembly, stabilization, or maintenance of the structural components of gap junctions. Although we cannot distinguish these possibilities at present, there are some indications in favor of the view that shaking- $B$ (neural) is not an invertebrate connexin. The high degree of homology between neural and lethal transcripts from the shaking- $B$ locus (see introductory remarks) suggests that they play similar roles (Crompton et al., 1995). Although shaking$B($ lethal $)$ is expressed widely and transiently in some embryonic mesodermal derivatives, this expression occurs after most cells have become uncoupled (Broadie and Bate, 1993; Tepass and Hartenstein, 1994) (for discussion, see Crompton ct al., 1995). shaking-B(lethal) is transcribed again in the developing pupal nervous system, including in the GFS, with maximum expression between $\sim 25$ and $60 \mathrm{hr}$ APF. Many of the neurons that express the gene during pupation eventually will make chemical synapses. Although these may establish transient gap junctions to mediate intercellular communication during pathfinding and target recognition (Myers and Bastiani, 1993; Peinado et al., 1993; Penn et al., 1994), it is unlikely that this could account for the very widespread expression observed at some stages (Crompton et al., 1995).

shaking $B$ is also homologous to another Drosophila gene, lethal (1) optic ganglion-reduced [l(1)ogre], and the Caenorhabditis elegans gene unc-7 (Crompton et al., 1995). l(1)ogre is required for postembryonic neurogenesis (Lipshitz and Kankel, 1985; Watanabe and Kankel, 1990); the protein appears to be located intracellularly (Watanabe and Kankel, 1992), which would rule out any involvement at gap junctions. One consequence of mutations in unc-7 is the formation of ectopic gap junctions between pairs of locomotory interneurons and motoneurons that generally are not coupled (Starich et al., 1993). This phenotype is inconsistent with a role for the protein as a structural component of a gap junction.

To predict, therefore, that shaking-B(neural) is a gap junction channel, one must assume functional diversity within this gene family. It is perhaps more likely that this group of homologous proteins is involved collectively in the organization of intercellular 
junctions or membrane apposition sites with shaking-B(neural) specialized for the organization of synaptic gap junctions.

\section{REFERENCES}

Bacon JP, Strausfeld NJ (1986) The Dipteran "giant fibre" pathway: neurons and signals. J Comp Physiol [A] 158:529-548.

Bainbridge SP, Bownes M (1981) Staging the metamorphosis of Drosophila melanogaster. J Embryol Exp Morphol 66:57-80.

Baird DI I, Koto M, Wyman RJ (1993) Dendritic reduction in Passover, a Drosophila mutant with a defective giant fibre neuronal pathway. J Neurobiol 24:971-984.

Baird DH, Schalet AP, Wyman RJ (1990) The Passover locus in Drosophila melanogaster: complex complementation and different effects on the giant fibre neural pathway. Genetics 126:1045-1059.

Balakrishnan R, Rodrigues V (1991) The shaker and shaking-B genes specify elements in the processing of gustatory information in Drosophila melanogaster. J Exp Biol 157:161-181.

Baptista CA, Macagno ER (1988) Modulation of the pattern of axonal projections of a leech motor neuron by ablation or transplantation of its target. Neuron 1:949-962.

Brand AH, Perrimon N (1993) Targeted gene expression as a means of altering cell fates and generating dominant phenotypes. Development $118: 401-415$.

Broadie KS, Bate M (1993) Development of the embryonic neuromuscular synapse of Drosophila melanogaster. J Neurosci 13:144--166.

Crompton DE, Griftin A, Davies JA, Miklos GLG (1992) Analysis of a CDNA from the neurologically active locus shaking-B (Passover) of Drosophila melanogaster. Gene 122:385-386.

Crompton DE, Todman MT, Wilkin MB, Ji S, Davies JA (1995) Essential and neural transcripts from the Drosophila shaking- $B$ locus are differentially expressed in the embryonic mesoderm and pupal nervous system. Dev Biol 170:142-158.

Fischer JA, Giniger E, Maniatis T, Ptashne M (1988) GAL4 activates transcription in Drosophila. Nature 332:853-856.

Goodman CS, Shatz CJ (1993) Developmental mechanisms that generate precise patterns of neuronal connectivity. Cell 72:77-98.

Halpern ME, Chiba A, Johansen J, Keshishian H (1991) Growth cone behaviour underlying the development of stereotypic synaptic connections in Drosophila embryos. J Neurosci 11:3227-3238.

Haydon PG, Drapeau P (1995) From contact to conncetion: carly events during synaptogenesis. Trends Neurosci 18:196-201.

Homyk T, Szidonya J, Suzuki DT (1980) Behavioural mutants of Drosophila melanogaster. III. Isolation and mapping of mutations by direct visual observation of behavioural phenotypes. Mol Gen Genet $177: 553-567$.

Ito K, Hotta Y (1992) Proliferation pattern of postembryonic neuroblasts in the brain of Drosophila melanogaster. Dev Biol 149:134-148.

King DG, Wyman RJ (1980) Anatomy of the giant fibre pathway in Drosophila. I. Three thoracic components of the pathway. J. Neurocytol 9:753-770.

Koto M, Tanouye MA, Ferrus A, Thomas JB, Wyman RJ (1981) The morphology of the cervical giant fibre neuron of Drosophila. Brain Res 221:213-217.

Krishnan SN, Frei E, Schalet AP, Wyman RJ (1995) Molecular basis of intracistronic complementation in the Passover locus of Drosophila. Proc Natl Acad Sci USA 92:2021-2025.

Krishnan SN, Frei E, Swain GP, Wyman RJ (1993) Passover: a gene required for synaptic connectivity in the giant fibre system of Drosophila. Cell 73:967-977.

Lipshitz HD, Kankel DR (1985) Specificity of gene action durıng central nervous system development in Drosophila melanogaster: analysis of the lethal (1) optic ganglion reduced locus. Dev Biol 108:56-77.
Martin KA, Poeck B, Roth H, Ebens AJ, Conley Ballard L, Zipursky SL (1995) Mutations disrupting neuronal connectivity in the Drosophila visual system. Neuron 14:229-240.

Myers CM, Whitington PM, Ball LE (1990) Embryonic development of the innervation of the locust extensor tibiae muscle by identified neurons: formation and elimination of inappropriate axon branches. Dev Biol 137:194-206.

Myers PZ, Bastiani MJ (1993) Cell-cell interactions during the migration of an identified commissural growth cone in the embryonic grasshopper. J Neurosci 13:115-126.

Nastuk MA, Fallon JR (1993) Agrin and the molecular choreography of synapse formation. Trends Neurosci 16:72-76.

Peinado A, Yuste R, Katz LC (1993) Extensive dye coupling between rat neocortical neurons during the period of circuit formation. Neuron 10:103 114.

Penn AA, Wong ROL, Shatz CJ (1994) Neuronal coupling in the developing mammalian retina. J Neurosci 14:3805-3815.

Phillis RW, Bramlage AT, Wotus C, Whittaker A, Grametes LS, Seppala D, Farahanchi F, Caruccio P, Murphey RK (1993) Isolation of mutants affecting neural circuitry required for grooming behaviour in Drosophila melanogaster. Genetics 133:581-592.

Power ME (1948) The thoracico-abdominal nervous system of an adult insect, Drosophila melanogaster. J Comp Neurol 88:347-419.

Raper Hummon M, Costello WJ (1987) Induced disruption in the connectivity of an identified neuron in the Drosophila ts mutant shibire. J Neurosci 7:3633-3638.

Schwarzman G, Wiegandt H, Rose B, Zimmerman A, Ben-Haim D, Loewenstein WR (1981) Diameter of the cell-10-cell junctional membrane chamels as probed with neutral molecules. Science 213:551-553.

Sink H, Whitington PM (1991a) Pathfinding in the central nervous system and periphery by identified embryonic Drosophila motor axons. Development 112:307-316.

Sink H, Whitington PM (1991b) Early ablation of target muscles modulates the arborization pattern of an identified embryonic Drosophila motor axon. Development 113:701-707.

Starich TA, Herman RK, Shaw JE (1993) Molecular and genetic analysis of unc-7, a Caenorhabditis elegans gene required for coordinated locomotion. Genetics 133:527-541.

Strausfeld NJ, Bassemir UK (1983) Cobalt-coupled ncurons of a giant fibre system in Diptera. J Neurocytol 12:971-991.

Tanouye MA, Wyman RJ (1980) Motor outputs of giant nerve fibre in Drosophila. J Neurophysiol 44:405-421.

Tepass U, Hartenstein $V$ (1994) The development of cellular junctions in the Drosophila embryo. Dev Biol 161:563-569.

Thomas JB, Wyman RJ (1994) Mutations altering synaptic connectivity between identified neurons in Drosophila. J Neurosci 14:530-538.

Truman JW, Bate M (1988) Spatial and temporal patterns of neurogenesis in the central nervous system of Drosophila melanogaster. Dev Biol 125:145-157.

Van Vactor D, Sink H, Fambrough D, Tsoo R, Goodman CS (1993) Genes that control neuromuscular specificity in Drosophila. Cell 73:1137-1153.

Watanabe T, Kankel DR (1990) Molecular cloning and analysis of $l(l)$ ogre, a locus of Drosophila melanogaster with prominent effects on the postembryonic development of the central nervous system. Genetics 126:1033-1044.

Watanabe T, Kankel DR (1992) The $/(l)$ ogre gene of Drosophila melanogaster is expressed in postembryonic neuroblasts. Dev Biol 152:172-183.

White K, Kankel DR (1978) Patterns of cell division and cell movement in the formation of the imaginal nervous system in Drosophila melanogaster. Dev Biol 65:296-321. 